\title{
Does Radio Advertisement Influence Sale of Herbal Products in Ghana? Evidence from Ho Municipality
}

\author{
Edward Kwame Ayimey ${ }^{1}$, Dadson Awunyo-Vitor ${ }^{2 *}$, John Korbla Gadawusu ${ }^{3}$ \\ ${ }^{1}$ Department of Marketing, Ho Polytechnic, Volta Region, Ghana \\ ${ }^{2}$ Department of Agricultural Economics, Agribusiness and Extension, Kwame Nkrumah University of \\ Science and Technology, Kumasi, Ghana \\ ${ }^{3}$ Ghana Broadcasting Corporation, Volta Region, Ghana \\ Email: Awunyovitor@yahoo.co.uk
}

Received August 4, 2013; revised September 2, 2013; accepted September 12, 2013

Copyright (C) 2013 Edward Kwame Ayimey et al. This is an open access article distributed under the Creative Commons Attribution License, which permits unrestricted use, distribution, and reproduction in any medium, provided the original work is properly cited.

\begin{abstract}
Radio as a medium of advertising is very popular among marketers of fast moving consumer goods because it can reach wider audience in both rural and urban areas. In recent times, the popularity of radio as an ideal medium of advertising is gaining ground among herbal medicine producers apparently for commercial gains. This study aimed at analyzing the effect of radio advertising on the sale of herbal products with specific reference to the Ho Municipality. Convenience sampling technique was used to sample the respondents. In all, data had been collected from a sample of 50 respondents comprising ten (10) herbal retail shop operators and forty (40) final consumers of herbal products. Interview guides were used to collect data from the management of herbal retail shops and questionnaires were used to collect data from the consumers of herbal products. Analytical tools used include descriptive statistics and correlation. The study revealed that the majority of consumers got to know of the products through radio advertisement. Also, empirical data analysis suggests that $60.7 \%$ of the sales of herbal products could be attributed to advertising. In view of the above findings, further studies may be directed towards identifying other factors that influence the sale of herbal products within the municipality.
\end{abstract}

Keywords: Radio Advertisement; Sales; Herbal Products; Ho Municipality; Ghana

\section{Introduction}

Promotion of business activities in general is an age-old practice. In the early days of civilization, human economic activities were given publicity through various means such as directional signs and display of names and symbols among others. These traditional methods have been improved upon to include modern forms of advertising such as in the print media (newspapers, magazines) and electronic media (television, radio, the internet and mobile phones amongst others). The multiplicity of sources of promotion has resulted in the practice whereby an advertiser has to make choices based on the ability of the medium of promotion to attract the target audience (Frank [1] 1994; Pearce and Robinson [2] 2009). In Ghana, just like other parts of the world, promotion of goods and services is becoming the norm. Promotions are done not only to attract consumers but also to inform, educate and gain competitive advantage over competitors and in-

${ }^{*}$ Corresponding author. crease overall market share and sales (Eiriz and Wilson [3] 2006). Most advertising messages direct customers to retail stores where the products can be bought. As a consequence, retailers engage in extensive promotional activities by engaging all kinds of media especially radio. Many products and services receive massive radio advertisements and are largely targeted at both rural and urban dwellers. A large number of these people listen to radio whilst doing other things (Rajagopal [4] 2010). In view of the huge listenership that radio communication enjoys, it has become a fertile ground for advertising of goods and services with the aim of improving sales. However, it must be noted that sales are influenced by many factors besides advertising, such as the product features, price, availability and competitors' actions etc. The fewer the controllable factors, the easier it is to measure advertising's effect on sales (Bennett and Rundle-Thiele [5] 2004; Kotler and Keller [6] 2006).

The listenership of radio and its influence on advertising have never been in dispute. In the United State of 
America for example over 92\% of the people aged 12 and above listen to radio each week, creating an audience of over 235 million listeners (Clow and Baack [7] 2007). Although specific verifiable figures are not readily available in the Ghanaian context, the issue is not debatable judging from the overwhelming commercial adverts running on radio stations. Consumers are said to react positively to radio commercials which are reflected in the sales at the advertiser's store outlets (Frank [1] 1994; Malhotra and Birks [8] 2007).

A lot of herbal products are advertised on radio in the Ho Municipality of the Volta Region of Ghana. Though the intensity of advertisement is said to correlate with consumer reaction in terms of awareness creation and patronage, it appears actual purchase does not grow proportionally with advertisement placed. The study therefore was to examine the extent to which radio advertisement influences sale of herbal products in the $\mathrm{Ho} \mathrm{Mu}-$ nicipality of the Volta Region of Ghana using Albertisam Enterprise as a case.

Albertisam Enterprise is a small-scale business entity which engages in wholesale and retailing of herbal products in the Volta Region. It started operation in 2002 as herbal shop but has since expanded the business to become a major wholesaling agent. Currently, the business is run by a work force of eight including the Managing Director. The company established a direct relationship with a number of herbal product manufacturers in Ghana. As a result of the cordial relationship built over the years, Albertisam Enterprise has gained the status of a major wholesaler of a variety of herbal products. The company takes an amount of supply from the various manufacturers and re-distributes them to small herbal shops. This is done by using its mobile vans to distribute the products to the various retailers usually on credit basis. After the distribution, the company embarks on intensive radio and other forms of advertising with emphasis on the products distributed. The ad messages centred on the product capabilities, benefits to prospective clients and the various retail outlets where the products are sold. Radio advertising for instance takes the form of jingles, announcements, and live commercial interviews. Though Albertisam Enterprise has been using radio advertising to promote its business activities, there has never been any study on its effectiveness. This study was conducted on the effect of radio advertising on the business's sales.

\section{Literature Review}

Advertisement of goods and services had been part of the business world over the centuries and several historical documents bear testimony to this. For instance, Berman [9] (2005), noted that commercial messages for sale of items have been found in the ruins of ancient Arabia. About four thousand years ago, ancient Egyptians were advertising by carving public notices on stones and using papyrus to make sales messages and wall posters. As the towns and cities grew during the middle ages, many people began to use symbols like hat, shoe, suit and other images associated with their trade as directional signs. Even proprietors who sold fruits and vegetables at the city square from the backs of carts and wagons used street callers (town criers) to announce their whereabouts (Rosenberg and Czepiel [10] 1984). With the expansion in education, more people were able to read and write. As a result of that, advertising expanded to include handbills. In the $18^{\text {th }}$ century, advertising started to appear in weekly newspapers in England. Radio and television advertising became popular when these media came into being in the 1920s and 1940s. The trend has continued with varying degrees of changes and innovations. Today, society in general is consistently bombarded with a multitude of advertising such as print fliers, posters, billboards, electronic banners, television and radio adverts, internet online ads, face book and mobile phone advertising among others.

Advertising is a form of communication used to persuade an audience (viewers, readers or listeners) to make them take an action with respect to a product. There are several definitions of advertising by various authors. The Advertising Association of UK states that "Advertising is the means of marking known in order to sell goods and services". This definition emphasizes the selling purpose of advertising. However, some other scholars are of the view that advertising is more embracing than selling alone. The Institute of Practitioners in Advertising describes advertising as the most persuasive possible selling message to the right prospect for the product or service at the lowest possible cost. While this description is broad and more probing, it only attempts to bring the essential elements of a good advert.

The most widely accepted definition of advertising is "any paid form of non-personal presentation and promotion of ideas, goods or services by an identified sponsor" (Kotler, Armstrong, Saunders and Wong, [11] 1999). This definition emphasizes the communication as well as the control aspect as may be directed by an identified sponsor in relation to the choice of medium, what is said, who said it, when it is said and how often it is said.

Advertisements are prepared for different purposes. For instance, product advertisement focuses on selling goods or services and based on the product's position on its life cycle, the advert may be tilted towards providing information, persuading and reminding or re-enforcing the good attributes of the product. At the introductory stages of the product life cycle, adverts are designed to give information about the product e.g. what it can do and where it can be found thus achieving the objective of providing information to the target consumers. Some- 
times, an advertisement may have the objective of promoting a specific brand's features and persuade the target market to select that product rather than that of the competitor. As the product grows along its life cycle, it matures and starts to decline. Reminder advertising is then used to reinforce previous knowledge of the product and also to assure current consumers that they have made the right choice. Advertising therefore disseminates information and helps bridge the information gap between the producer and the consumer (Berkowitz, Kerin, Hartley and Rudelius [12] 2000).

Advertising aims must be sloping around the communication process. The communication task is to build up brand alertness, altering consumer thoughts and informing customers about product dimensions and properties. The elementary purpose of advertising is to boost sales of a product. As a promotional technique, advertising augments the tendency to purchase, moving the prospect gradually towards the product to make a purchase decision. It motivates the buyer through consecutive stages such as awareness, comprehension or recognition, conviction and action. Advertising objectives may be divided into four stages of commercial communication which are awareness, conception, apprehension, conviction and action. Awareness creation is the bare minimum goal of advertising. The buying process starts after informing the consumer about the product. Conception is the communication level where the prospect understands what the product is and what it will do for him. The apprehension level indicates that people are aware of the brand i.e. the brand name, the package or trademark. The conviction level shows brand preference and the prospect's intention to buy the product in the near future. At the action level, the prospect takes meaningful action by buying the product.

Theories on consumer behaviour state inter alia that the behaviour of people are influenced by both external factors like viewing, listening and reading in addition to individual state of mind including feeling and cognition. Understanding the buying behaviour of the target consumer is a very essential concept in marketing goods and services. The consumer is the user of the product and could be an individual, a household or an organization that buys or acquire goods and services for consumption or for reuse.

Consumers vary greatly in age, income, educational level, mobility patterns and taste and these greatly affect their behaviour. It is therefore useful to distinguish different consumer groups or segments and develop products tailored to their needs (Kotler [13] 1991). Since consumers buy a variety of goods and services, it is important to try to understand how they make their purchase choices. This calls for appreciation of the factors that influence the buyer's purchase decision such as cul- ture, social, personal and psychological factors.

One of the conceptual frameworks used to explain the consumer's thought process is the hierarchy-of-effects model (See Figure 1). This framework describes the effects of advertising on consumers. It is posited that advertising has multiple tasks.

The hierarchy-of-effects model shows the buyer as progressing through awareness, knowledge, liking, preference, conviction and purchase. Awareness creation is the initial task for communication. If most of the target audiences are unaware of the product, the communicator's task is to build awareness, perhaps by just name recognition. At this level, the target audience might have product awareness but do not know much more. Liking involves developing favourable feelings about the product. Thus, target members who know of the product must be able to show their feelings about it. The target audience might like the product but not prefer it to others. In this case, the communicator must try to build consumer preference. The communicator should promote the product's quality, value, performance and other features. The success of such a campaign can be checked by measuring audience preference before and after the campaign.

A target audience might prefer a particular product but not develop a conviction about buying it. The job of the communicator is to convince the target audience that selecting that product is the right thing to do. Finally, some members of the target audience might have conviction but may not purchase the product. They may wait for more information or plan to act later. The communicator must lead these consumers to take a purchase action.

A more basic conceptual model used to illustrate the consumer's thought process is AIDA an acronym for Attention, Interest, Desire and Action. The main AIDA influence is the ability of the communication or advertisement to hold attention and drive the prospect into action. The use of the AIDA communication concept also helps retailing stores and brands to stand out in the com-

\begin{tabular}{cc}
\hline Stages & Hierarchy-of-Effects \\
\hline Cognitive stage & Awareness \\
\hline Affective stage & Knowledge \\
\hline Behaviour stage & Conviction \\
\hline
\end{tabular}

Figure 1. Conceptual framework of consumer thought process (Hierarchy-of-effects model). Source: Kotler, [13] (1991). 
petition and make advertisements more memorable as well as enhancing brand awareness, especially for desired products (Richardson [14] 2006).

A supporting model and paradigm of consumer behaviour is ACCA which stands for Awareness, Comprehension, Conviction and Action. This model postulates that, when awareness on the sales promotion converges with the content of advertisements, it generates conviction among consumers which leans towards actions that result into the choice and buying decision (Rajagopal [4] 2010). It is strongly believed that accurate and acceptable information can effectively lead to consumer's conviction towards buying decision and action of actual purchase (Callen-Marchione and Ownbey [15] 2008).

\section{Methodology}

This research was conducted in the Ho Municipality of the Volta Region of Ghana. It covered ten (10) retail shops which deal in herbal products and forty (40) final consumers of herbal products. Convenience sampling procedure was adopted in selecting the respondents for the study because it is more appropriate than other techniques looking at the objective of the study.

Questionnaire and interview guides were used to collect data from the respondents. Interview guides were used to collect data from the management of herbal retail shops while questionnaires were used to collect data from sampled final consumers of herbal products. The data collected was analysed using correlation and regression analyses to establish the relationship between radio advertising expenditure and sales concerning the herbal products of the case under study. Statistical Package for Social Sciences (SPSS) was used for the respective analyses.

\section{Results and Discussions}

\subsection{Advertising Media Used by the Herbal Retail Shops}

This section discusses the data collected from retailers to determine the popularity of radio as a medium for advertising herbal products.

From Table 1, the most preferred medium of advertisement employed by retailers of herbal products is radio advertisement. None of the retailers mentioned any other medium apart from TV (10\%) and radio (90\%) as indicated in Table 1. The reasons for preference for radio as an advertising medium are presented in Table 2.

Majority of retailers (80\%) of herbal products consider radio as the most preferred medium for advertising herbal medicines because it is easily accessible to their target audience (Table 2). However, few retailers (20\%) mentioned that the reason for preferring radio advertising to others is that it is possible to use radio to communicate timely and relevant information to their audience. In addition, all the respondents are of the view that radio advertisement attracts buyers to their shops. This is because they all believe that a lot of people listen to radio and so through that, they hear of their products and come to buy. In view of this, all the respondents expect that there will be more radio advertisements for their products by the producers or wholesalers in the future. This is because majority (80\%) believe that advertisement makes their products popular and others (20\%) believe that advertisement helps in selling their products as shown in Table 3.

The findings show clearly that the retailers of herbal products believe strongly that radio advertising is a factor that influences customers to buy their herbal products.

\subsection{The Relationship between Radio Advertising Expenditure and Sales}

This section deals with the analysis of the secondary data collected. Data had been collected on sales and their respective radio advertisement expenditure within 5 years (2007 to 2011) on monthly bases. The purpose is to investigate the relationship between sales and radio advertising expenditure.

Table 1. Preferred medium of advertisement.

\begin{tabular}{ccc}
\hline Medium of advert & Frequency & Percent \\
\hline TV & 1 & 10.0 \\
Radio & 9 & 90.0 \\
Total & $\mathbf{1 0}$ & $\mathbf{1 0 0 . 0}$ \\
\hline
\end{tabular}

Source: Field data, 2012.

Table 2. Reasons for preferring radio as a medium of advertisement.

\begin{tabular}{ccc}
\hline Reason & Frequency & Percent \\
\hline $\begin{array}{c}\text { It is easily accessible } \\
\text { It provides timely and relevant } \\
\text { information } \\
\text { Total }\end{array}$ & 8 & 80.0 \\
\hline
\end{tabular}

Source: Field data, 2012.

Table 3. Importance of advert to selling.

\begin{tabular}{ccc}
\hline Importance & Frequency & Percent \\
\hline Advertising makes products popular & 8 & 80.0 \\
Advertising helps to sell the products & 2 & 20.0 \\
Total & $\mathbf{1 0}$ & $\mathbf{1 0 0 . 0}$ \\
\hline
\end{tabular}

Source: Field data, 2012. 
Figure 2 below is a scatter plot of radio advertising expenditure against sales. The coefficient suggests that there exists a somewhat positive relationship between radio advertisement and sales. It is generally observed that, as radio advertisement expenditure increases, there is a general corresponding increase in sales indicating that, advertisement has some form of positive influence on sales. Of note however are some extreme values in the scatter plot indicating that there is the likeliness of obtaining a large variability in the data set which cannot be well explained by the independent variable (radio advertising expenditure).

The descriptive statistics shows the mean and standard deviation values of both the dependent variable (sales) and independent variable (radio advertising expenditure). It means the average sales value for the period under consideration is GHథ 2441.55 when averagely, GH\$ 419.05 was spent on radio advertisement. The variability however is large as shown by the standard deviations.

Both Tables $\mathbf{4}$ and $\mathbf{5}$ produce a correlation coefficient above 0.5 which indicates quite a strong relationship between the variables. The Pearson's correlation coefficient of 0.738 obtained in Table 4 matches that obtained in the regression model of Table $\mathbf{5}$. This is supported by the one-tailed significant figure (p-value) of 0.000 . Also, the beta value of 3.979 indicates the degree of effect of the independent variable (radio advertising expenditure) on dependent variable (sales) with a constant value of

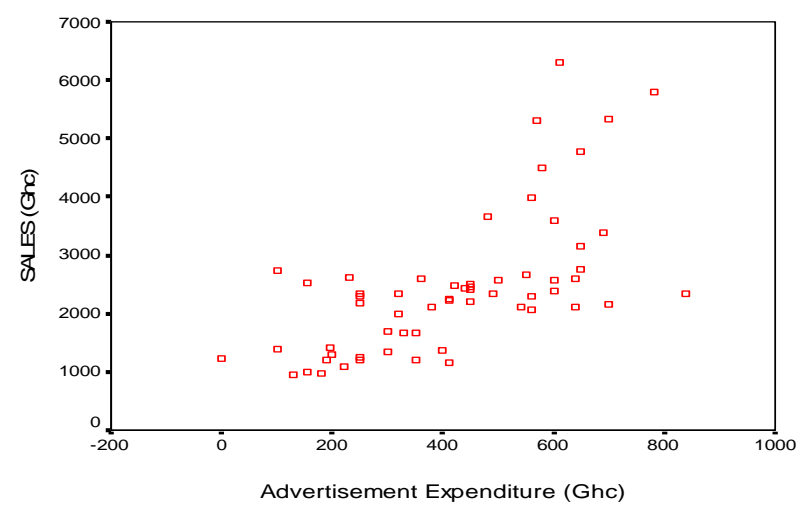

Figure 2. Scatter plot of radio advertisement expenditure against sales.

Table 4. Correlations between radio advertising expenditure and sales.

\begin{tabular}{ccc}
\hline Factors & Correlation Tests & Sales \\
& Pearson Correlation & $0.738^{*}$ \\
Advertising & Sig. (2-tailed) & 0.000 \\
Expenditure & $\mathrm{N}$ & 60 \\
\hline
\end{tabular}

*Correlation is significant at the 0.05 level.
Table 5. Regression model for radio advertising expenditure and sales.

\begin{tabular}{ccccc}
\hline & Coefficient & $\begin{array}{c}\text { Std. } \\
\text { Error }\end{array}$ & t-Statistics & P-Value \\
\hline (Constant) & 774.271 & 290.579 & 2.665 & 0.010 \\
Advertisement & 3.979 & 0.631 & 6.306 & 0.000 \\
& \multicolumn{5}{c}{ Diagnostic Statistics } \\
R Square & Adjusted R Square & $\begin{array}{c}\text { Std. Error of the } \\
\text { Estimate }\end{array}$ & Durbin-Watson \\
0.607 & 0.597 & 933.880 & 0.589 \\
\hline
\end{tabular}

Dependent variable: SALES. Source: Field data, 2012.

774.271. The constant indicates that when the effect of the independent variable (radio advertising expenditure) is nullified, the average minimum value of the dependent variable (sales) would be 774.271. According to the model summary of Table 5, the R Square value of 0.607 indicates that the model could explain only $60.7 \%$ of the total variability in the data set indicating that there may be some other variable(s) that are responsible for the dependent variable's occurrence.

\subsection{The Effect of Radio Advertising on Buyer Behaviour of Final Consumers}

This part of the analysis investigated the effect that advertisement has on the purchasing behavior of final consumers of herbal products. It attempted to discover what effect radio advertising has on the behaviour of final consumers. The goal is to establish the extent to which the purchases of herbal products are influenced by radio advertisement.

All the respondents investigated have ever bought a herbal product before with $70 \%$ of such purchase taking place in herbal shops. However, a few others (27\%) also buy from sales vans. These represent the two main sources of herbal medicine procurement by consumers. This is shown in Table 6.

From Table 7, majority of the respondents (70\%) got to know of the herbal medicines they procured through radio advertisement. This is quite revealing in the face of the fact that other media such as poster, television and newspapers were also used for advertising herbal products.

It is observed that ninety five percent (95\%) of the respondents see advertisement as a very helpful tool to consumers (Table 8). It is not surprising therefore that at least $50 \%$ of retailers stock products that receive advertising support.

With reference to Table 9, it is observed that the most preferred medium for herbal medicine advertisement is radio. The main reason adduced by the respondents 
Table 6. Sources of herbal medicine procurement.

\begin{tabular}{ccc}
\hline Sources & Frequency & Percent \\
\hline Herbal store & 28 & 70.0 \\
Sales van & 11 & 27.5 \\
Herbal clinic/herbalist & 1 & 2.5 \\
Total & $\mathbf{4 0}$ & $\mathbf{1 0 0 . 0}$ \\
\hline
\end{tabular}

Source: Field data, 2012.

Table 7. Advertising media that reached the final consumer.

\begin{tabular}{ccc}
\hline Advertising Media & Frequency & Percent \\
\hline Poster & 5 & 12.5 \\
Radio & 28 & 70.0 \\
TV & 7 & 17.5 \\
Total & $\mathbf{4 0}$ & $\mathbf{1 0 0 . 0}$ \\
\hline
\end{tabular}

Source: Field data, 2012.

Table 8. Helpful nature of advertisement.

\begin{tabular}{ccc}
\hline Response & Frequency & Percent \\
\hline It is not helpful & 2 & 5.0 \\
It is very helpful & 38 & 95.0 \\
Total & $\mathbf{4 0}$ & $\mathbf{1 0 0 . 0}$ \\
\hline
\end{tabular}

Source: Field data, 2012.

Table 9. Preferred advertising media.

\begin{tabular}{ccc}
\hline Media & Frequency & Percent \\
\hline Radio & 23 & 57.5 \\
TV & 13 & 32.5 \\
Posters & 4 & 10.0 \\
Total & $\mathbf{4 0}$ & $\mathbf{1 0 0 . 0}$ \\
\hline
\end{tabular}

Source: Field data, 2012.

(61\%) for this is that a lot of people listen to radio and for this reason, majority of the respondents see radio as the best medium for advertising herbal medicines. Quite a significant number of the respondents (35\%) also said they prefer radio because it is easily available. This is shown in Table 10.

The study also found out the influence of radio advertising on the purchase decision-making of final consumers of herbal products. Notwithstanding, the possible influence of other factors that affect consumers' purchase decision-making process, the researchers found out the influence of radio advertising.

Almost all the final consumers sampled (95\%) said radio adverts influenced them a lot in the choice of herbal products they buy (Table 11). This is because herbal medicine advertisements through radio provide them with important information to aid their purchase decisions as depicted in the Table 12 below. Only 5\% of the respondents in this case indicated that radio advertising did not influence their decision to purchase herbal products.

\section{Conclusions and Recommendations}

Radio is an ideal medium for marketing herbal products because it can reach many members of a company's target audience in the urban, semi-urban and rural areas. It is clear from the study that, radio advertisement of herbal products influences the type of products bought because such adverts provide important information that aids buying decisions. In analyzing the relationship between radio advertising expenditure and sales, the study points to a positive correlation between the two variables. This implies that, as advertising expenditure rises, there is a general corresponding increase in sales. The $60.70 \%$ increase in sales can be attributed to radio advertisement.

Table 10. Reasons for the preferred advertising media.

\begin{tabular}{ccc}
\hline Reasons & Frequency & Percent \\
\hline Radio is easily available & 8 & 35.0 \\
A lot of people listen to radio & 14 & 61.0 \\
Radio is less expensive & 1 & 4.0 \\
Total & $\mathbf{2 3}$ & $\mathbf{1 0 0 . 0}$ \\
\hline
\end{tabular}

Source: Field data, 2012.

Table 11. Influence of radio adverts on the type of herbal product to buy.

\begin{tabular}{ccc}
\hline Influence & Frequency & Percent \\
\hline $\begin{array}{c}\text { Radio advert has a strong } \\
\text { influence }\end{array}$ & 38 & 95.0 \\
$\begin{array}{c}\text { Radio advert has no influence } \\
\text { Total }\end{array}$ & 2 & 5.0 \\
\hline
\end{tabular}

Source: Field data, 2012.

Table 12. The effect of radio advertising on herbal product choice.

\begin{tabular}{ccc} 
Influence & Frequency Percent \\
Provide important information & 36 & 90.0 \\
Education on the ingredients used & 2 & 5.0 \\
$\begin{array}{c}\text { Advocating the replacement of orthodox } \\
\text { medicine with herbal medicine }\end{array}$ & 2 & 5.0 \\
Total & $\mathbf{4 0}$ & $\mathbf{1 0 0 . 0}$ \\
\hline
\end{tabular}

Source: Field data, 2012. 
This implies that, there are other factors that influence the sale of herbal products apart from radio advertising. Also, it is evident from the study that the majority of herbal product users rely on radio as source of information and radio adverts influence their decisions to purchase herbal products.

Herbal medicines have been of great concern to the general public and the government of Ghana due to their crucial role in healthcare delivery in the country. Herbal medicine serves as an alternative to orthodox medicine by providing quality healthcare delivery to the citizenry. It is important therefore to devote more attention to promotion of herbal products in Ghana in order to maximize the medical and economic potentials of herbal products in the country. Producers and distributors of herbal products in Ghana should take advantage and develop very attractive radio adverts for the attraction of the consumers. In doing so, creative advertising copywriters should be engaged to create persuasive radio adverts and buy radio time appropriately so as to boost sale of herbal products in Ghana.

\section{REFERENCES}

[1] J. Frank, "Modern Marketing," Pitman Publishing, London, 1994, pp. 24-41.

[2] J. A. Pearce and R. B. Robinson, "Strategic Management, Formulation, Implementation and Control," 11th Edition, McGraw-Hill International, New York, 2009, pp. 21-25.

[3] V. Eiriz and D. Wilson, "Research in Relationship Marketing: Antecedents, Traditions and Integration," European Journal of Marketing, Vol. 4, No. 4, 2006, pp. 275291. http://dx.doi.org/10.1108/03090560610648057

[4] J. Rajagopal, "Role of Radio Advertisements as Behavioral Driver among Urban Consumers,” Graduate School of Administration and Management (EGADE) Monterrey Institute of Technology and Higher Education, ITESM Working Paper, 2010.
[5] R. Bennett and S. Rundle-Thiele, "Customer Satisfaction Should Not Be the Only Goal,” Journal of Services Marketing, Vol. 18, No. 7, 2004, pp. 514-523. http://dx.doi.org/10.1108/08876040410561848

[6] P. Kotler and K. L. Keller, "Marketing Management," 12th Edition, Pearson Prentice Hall, London, 2006, pp. 105-108.

[7] E. K. Clow and D. Baack, "Integrated Advertising, Promotion, and Marketing Communications,” Pearson, Prentice Hall, New York, 2007, pp. 52-67.

[8] N. K. Malhotra and D. F. Birks, "Marketing Research: An Applied Approach,” 3rd European Edition, Prentice Hall, London, 2007, pp. 58-64.

[9] B. Berman, "How to Delight Your Customers," California Management Review, Vol. 48, No. 1, 2005, pp. 210 221. http://dx.doi.org/10.2307/41166331

[10] L. J. Rosenberg and J. A. Czepiel, “A Marketing Approach for Customer Retention,” Journal of Consumer Marketing, Vol. 1, No. 2, 1984, pp. 45-51. http://dx.doi.org/10.1108/eb008094

[11] P. Kotler, G. Armstrong, J. Saunders and V. Wong, "Principles of Marketing,” Prentice-Hall, Cambridge, 1999, pp. 98-102.

[12] E. N. Berkowitz, R. A. Kerin, S. W. Hartley and W. Rudelius, "Marketing," 6th Edition, McGraw-Hill, London, 2000, pp. 12-24.

[13] P. Kotler, "Marketing Management: Analysis, Planning, Implementation and Control,” Prentice-Hall, London, 1991, pp. 125-136.

[14] M. Richardson, "Commercial Broadcasting and Local Content: Cultural Quotas, Advertising and Public Stations," Economic Journal, Vol. 116, No. 15, 2006, pp. 605-625. http://dx.doi.org/10.1111/j.1468-0297.2006.01094.x

[15] K. S. Callen-Marchione and S. F. Ownbey, "Association of Unethical Consumer Behavior and Social Attitudes," Journal of Fashion Marketing and Management, Vol. 12, No. 3, 2008. pp. 365-383.

http://dx.doi.org/10.1108/13612020810889317 